\title{
Lack of effect of dihydroergotamine on endothelial and smooth muscle cell proliferation and endothelial cell prostanoid production
}

\author{
B. Lindblad ${ }^{\text {a, *, W. E. Burkel }}{ }^{\mathbf{b}}$, T. W. Wakefield ${ }^{\mathbf{b}}$, L. M. Graham ${ }^{\mathbf{a}}$ and J. C. Stanley ${ }^{\mathbf{a}}$ \\ ${ }^{a}$ Departments of Surgery and ${ }^{b}$ Anatomy and Cell Biology, University of Michigan Medical School, Ann Arbor (Michigan, \\ USA) \\ Received 8 July 1987; accepted 22 October 1987
}

Summary. The most important effect of dihydroergotamine is venoconstriction, but certain metabolic effects and changes in vessel prostanoid activity have also been suggested. In this study endothelial cell production of 6-keto PGF $\mathrm{Pa}_{1 a}$ and TxB was quantitated in vitro. No evidence of altered prostanoid production was noted after incubation with dihydroergotamine (exposure ranging from $5 \times 10^{-3}$ to $\left.5 \times 10^{-7} \mathrm{~g} / 1\right)$. Similarly, no effect of dihydroergotamine on the growth rates of endothelial cells or smooth muscle cells in vitro was documented.

Key words. Dihydroergotamine; endothelial cells; smooth muscle cell; prostanoid production.

Dihydroergotamine (DHE), a dihydrogenated ergot alkaloid, has potential clinical usefulness in treating a variety of vascular diseases. Among its effects are hemodynamic alterations induced by interaction with $\alpha$-adrenoreceptors. This effect of DHE can only partly be blocked by phentolamine, thus differentiating it from that of noradrenaline. The remaining tension can be blocked by inhibitors of the prostanoid system ${ }^{1-3}$. In this regard, fluid in which vein strips are immersed after administering DHE contains increased activity of a prostanoid E-like substance ${ }^{2}$. Similarly, increased production of prostacyclin has been reported in immersion fluid from DHE treated rabbit vessels ${ }^{4}$ and in human veins in vitro ${ }^{5}$. This effect on prostanoids could not be verified in an in vivo study on healthy volunteers ${ }^{6}$. Thus the question arises: does DHE cause prostanoid release? In addition DHE induces metabolic changes that theoretically could interfere with cell metabolism and cell replication ${ }^{7}$. This study was undertaken to ascertain whether DHE had any effect on endothelial or smooth muscle cell proliferation, or endothelial cell prostanoid synthesis in vitro.

Material and methods. Endothelial and smooth muscle cell derivation. Endothelial cells from dog external jugular veins were harvested enzymatically with trypsin and collagenase as previously described by Ford et al. ${ }^{8}$. A homogeneous endothelial cell culture was ascertained by morphologic study and factor VIII expression.

Smooth muscle cells were derived from canine carotid arteries. They were cleaned of adventitia and endothelium, minced, and placed into an enzyme solution of elastase type III and collagenase CLS type I. The high purity of the cell cultures was ascertained by morphological characterization, including presence of numerous myofilament bundles in the cytoplasm and vesicles near the membranes. For details of methodology see Lindblad et al. ${ }^{11}$.

Endothelial and smooth muscle cell grow th rate determination. Primary endothelial cell cultures, after 7-10 days growth, were trypsinized, pooled, passed and placed in serum-coated 16-mm culture wells (Costar, Cambridge, MA, USA), at a density of approximately 10,000 cells/well. The medium was medium 199, with $20 \%$ fetal bovine serum (FlowLab, Rockville, MD, USA), gentamicin $(5 \mu \mathrm{g} / \mathrm{ml}$, Schering, Kenilworth, NJ, USA), and a high concentration of endothelial cell growth factor $(100 \mu \mathrm{g} / \mathrm{ml}$, Seragen, Boston, MA, USA). No heparin was added to this medium. Dihydroergotamine mesylate (DHE 45, Sandoz Inc., East Hanover, NJ, USA) was added to the medium, at concentrations of $5 \times 10^{-3}$; $5 \times 10^{-4} ; 5 \times 10^{-5} ; 5 \times 10^{-6}$; and $5 \times 10^{-7} \mathrm{~g} / 1$. Medium without DHE served as a control. Sixteen wells were used for each DHE concentration studied. These DHE concentrations ranged from 1000 times higher to 10 times lower than the plasma concentration normally achieved in clinical settings. Addition of DHE did not affect the $\mathrm{pH}$ of the medium. The nutrient medium, with or without DHE, was changed every other day during the cultivation period.

Smooth muscle cells, after primary cultivation, were trypsinized, pooled, washed, spun, and resuspended in medium as above. Into each 16-mm tissue culture well 8000 cells were plated. Different concentrations of DHE were added giving a final concentration of DHE ranging from $5 \times 10^{-3}$ to $5 \times 10^{-7} \mathrm{~g} / 1$. In a control group no DHE was added. Both endothelial and smooth muscle cell cultures were maintained in a $37^{\circ} \mathrm{C}$ incubator with a $100 \%$ humidified atmosphere gas consisting of $5 \% \mathrm{CO}_{2}$ and $95 \%$ air.

Initial seeding density was determined for 24 samples taken during plating. Plating efficiency was measured from 4 wells trypsinized at day 3 . At the end of 7 days the remaining cells (12 wells) were trypsinized and counted using a Coulter ${ }^{\circledR}$ counter.

Endothelial cell prostanoid production. The endothelial cell culture medium was changed on day 6 , and on day 7 the medium incubated for $24 \mathrm{~h}$ with the cells was removed and immediately frozen for later assay of prostanoid production. Prostanoid metabolites were determined after extraction of proteins and free fatty acids ${ }^{9}$. 6-keto $\mathrm{PGF}_{1 \alpha}$ was determined utilizing a radioimmunoassay kit (New England Nuclear, detection limit $3.8 \mathrm{pg}$ ). $\mathrm{TxB}_{2}$ was also determined by radioimmunoassay (New England Nuclear, detection limit $0.5 \mathrm{pg}$ ). The assays have low cross-reactivity to related prostanoids ${ }^{9}$. Statistical analysis was performed with the Wilcoxon rank sum test. Mean values \pm SEM are given.

Results. Endothelial cell growth (table). The mean initial seeding density for the endothelial cells was 11,206 \pm 253 / well. Plating efficiency measured at day 3 did not differ markedly, being $15,162 \pm 765-16,376 \pm 534$. This cell density increased approximately 15 -fold by the 7 th day being $158,300 \pm 1,315$ in control wells. No difference between the

Endothelial cell and smooth muscle cell growth ${ }^{*}$, at 7 days from an initial cell density of $11,206 \pm 253$ and $7613 \pm 176$ cells, respectively ( $\mathrm{n}=12$, $\times \pm$ SEM)

\begin{tabular}{lllllll}
\hline & \multicolumn{2}{l}{ Dihydroergotamine concentration $(\mathrm{g} / \mathrm{l})$} & & \\
& $5 \times 10^{-3}$ & $5 \times 10^{-4}$ & $5 \times 10^{-5}$ & $5 \times 10^{-6}$ & $5 \times 10^{-7}$ \\
\hline Endothelial & 153,530 & 159,370 & 151,745 & 167,594 & 166,370 & None (control) \\
cells & \pm 1120 & \pm 860 & \pm 1710 & \pm 2060 & \pm 1625 & 158,300 \\
Smooth & 9036 & 9051 & 8876 & 8872 & 8963 & \pm 1315 \\
muscle cells & \pm 389 & \pm 288 & \pm 421 & \pm 332 & \pm 312 & \pm 246 \\
\hline
\end{tabular}

* No statistically significant differences, comparing any concentration of DHE to controls. 
groups which were exposed to different DHE levels was seen (range 151,745 $\pm 1710-167,594 \pm 2060$ cells/well). Examination of cells by phase contrast microscopy revealed no changes that could be ascribed to DHE.

Smooth muscle cell growth (table). Initial seeding density of smooth muscle was $7613 \pm 176$ cells/well. Plating efficiency measured at day 3 did not differ markedly being $5865 \pm 380-5976 \pm 412$. By day 7 after seeding, the cell count had increased, with control wells containing $9017 \pm 246$ cells and DHE treated wells between $8872 \pm 332$ and $9051 \pm 288$ cells. Phase contrast microscopy revealed no changes in cell configuration.

Endothelial cell prostanoid production. The 24-h incubated media had concentrations of 6-keto PGF $_{1 \alpha}$ of $3380 \pm$ $380 \mathrm{pg} / \mathrm{ml}$ in controls, and a range of $3160 \pm 425-3370 \pm$ $510 \mathrm{pg} / \mathrm{ml}$ in DHE wells. TxB ${ }_{2}$ levels were $5810 \pm 1020 \mathrm{pg} /$ $\mathrm{ml}$ in controls and ranged from $4210 \pm 1400$ to $6960 \pm$ $1310 \mathrm{pg} / \mathrm{ml}$ in DHE wells. No significant differences existed between control medium and that to which DHE had been added.

Discussion. In the current study we could not verify increased activity of prostanoids in vitro from cultured endothelial cells exposed to DHE. We have reported previously on the effects in vivo on healthy volunteers of indomethacin pretreatment before DHE administration. After pretreatment the same hemodynamic effects were observed as with no pretreatment; namely, increased venous flow velocity, reduced venous cross-sectional area, and reduced resting calf blood flow volume ${ }^{6,10}$. These results, contrary to those of others, suggest little importance of prostanoids in the action of DHE. Measured under identical conditions, other agents show substantial variation in the prostanoid activity. Reduced release of prostanoids has been noted for acetylsalicylic acid $(-55 \%)$ and other cyclooxygenase and thromboxane inhibitors, whereas dipyridamole, a phosphodiesterase inhibitor, did not alter prostanoid activity, and thrombin administration increased prostanoid activity ${ }^{11}$. In addition to the direct vascular effects of DHE, metabolic alterations have also been ascribed to DHE. Included among these are reductions in liver glucose output, inhibition of adrenaline-induced hyperglycemia, stimulation of lipolysis, inhibition of cAMP degradation, interference with phosphodiesterase and increased pyruvate/lactate ratio during relative hypoxia ${ }^{7,12}$. Because of the potential effect of these changes on cell growth, we attempted to define whether there was any interaction between DHE and in vitro endothelial or smooth muscle plating efficiency and cell proliferation. Our data show that no such effect exists in this setting.

* Present address: Department of Surgery, University of Lund, Malmö General Hospital, S-21401 Malmö, Sweden.

1 Müller-Schweinitzer, E., and Brundell, J., Eur. J. Pharmac. 34 (1975) 194.

2 Müller-Schweinitzer, E., and Brundell, J., Blood Vessels 12 (1975) 193.

3 Müller-Schweinitzer, E., and Stürmer, E., Br. J. Pharmac. 51 (1974) 441.

4 Silberbauer, K., Fitscha, P., and Sinzinger, H., W. Klin. Wschr. 95 (1981) 577.

5 Sinzinger, H., Thromb. Haemost. 53 (1985) 285.

6 Bergqvist, D., and Lindblad, B., Ups. J. med. Sci. 89 (1984) 227.

7 Wagner, H., in: Ergot Alkaloids and Related Compounds, p. 691. Eds B. O. Berde and H. O. Schild. Springer Verlag, Berlin-HeidelbergNew York 1978

8 Ford, J. W., Burkel, W. E., and Kahn, R. H., In Vitro 17 (1981) 44.

9 Fitzpatrick, F. A., and Wynalda, M. A., Analyt. Biochem. 73 (1976) 198.

10 Lindblad, B., Bergqvist, D., Efsing, H. O., Hallböök, T., and Lindell, S.-E., VASA 13 (1984) 165.

11 Lindblad, B., Burkel, W. E., Graham, L. M., Darvishian, D., Harrell, K., Sell, R., and Stanley, J. C., Cell Tissue Kinet. (1987) in press.

12 Loew, D. M., van Deüsen, E. B. and Meier-Ruge, W., in: Ergot Alkaloids and Related Compounds, p. 421. Eds B. Berde and H. O. Schild. Springer Verlag, Berlin-Heidelberg-New York 1978.

0014-4754/88/030223-02\$1.50+0.20/0

(C) Birkhäuser Verlag Basel, 1988

\section{Inhibition by tetanus and botulinum $A$ toxin of the release of $\left[{ }^{3} \mathrm{H}\right]$ noradrenaline and $\left[{ }^{3} \mathrm{H}\right] \mathrm{GABA}$ from rat brain homogenate}

\section{E. Habermann}

Buchheim-Institut für Pharmakologie der Justus-Liebig-Universität, Frankfurter Str. 107, D-6300 Giessen (Federal Republic of Germany)

Received 7 September 1987; accepted 23 November 1987

Summary. Rat brain homogenate was preloaded with $\left[{ }^{3} \mathrm{H}\right]$ noradrenaline or $\left[{ }^{3} \mathrm{H}\right] \mathrm{GABA}$ and stimulated with high $\mathrm{K}^{+}$ Tetanus toxin and botulinum A neurotoxin partially prevent the evoked $\left[{ }^{3} \mathrm{H}\right]$ noradrenaline release in the same range of toxin concentrations starting below $10^{-10} \mathrm{M}$. In contrast, release of $\gamma$-amino butyric acid (GABA) is much more sensitive to tetanus than to botulinum A toxin.

Key words. Tetanus toxin; botulinum toxin; noradrenaline; GABA; brain.

Recently it has been claimed ${ }^{1}$ that tetanus toxin does not inhibit the evoked release of $\left[{ }^{3} \mathrm{H}\right]$ noradrenaline from rat cerebral cortex slices. The statement contradicts our positive findings, obtained using two different experimental designs, on rat brain homogenate ${ }^{2,3}$. Using an improved superfusion system, we now show that both tetanus and, still better, botulinum $A$ toxin prevent noradrenaline release. In contrast, the release of GABA, which is known as an inhibitory neurotransmitter, is inhibited preferentially by tetanus toxin. Method. Rat brain cortex was cut into $0.3 \times 0.3 \mathrm{~mm}$ prisms with a McIlwain chopper and suspended in Hepes $(10 \mathrm{mM}$,
pH 7.4) buffered ice-cold Krebs-Ringer solution (KRH). After a short trituration with an Eppendorf pipette, the suspension $(10 \% \mathrm{w} / \mathrm{v})$ was passed three times by hand through a Potter homogenizer with a loose-fitting pestle. After $3 \mathrm{~min}$ centrifugation at $4500 \times \mathrm{g}$ and washing once, the sediment was taken up to give $2 \%(\mathrm{w} / \mathrm{v})$ with respect to original weight. For studying noradrenaline release, this suspension was mixed with half its volume of $\mathrm{KRH}$ containing (final concentration) noradrenaline $(1 \mathrm{mCi} / 1,1 \mu \mathrm{M})$, iproniazid $(10 \mu \mathrm{M})$ and ascorbic acid $(20 \mu \mathrm{M})$. All subsequent solutions contained iproniazid and ascorbic acid. After $15 \mathrm{~min}$ shak- 